\title{
Systematic review finds that fever phobia is a worldwide issue among caregivers and healthcare providers
}

\section{Short title: fever phobia - systematic review}

Clericetti Caterina M.12*, MD; Milani Gregorio P.2*, MD; Bianchetti Mario G.1,3, MD; Simonetti Giacomo D.1,3, MD; Fossali Emilio F.4 , MD; Balestra Alessandra M.1, MD, Bozzini MarieAnge $^{5}$, MD, Agostoni Carlo², MD, Lava Sebastiano A. G.5 , MD MSC

${ }^{1}$ Pediatric Department of Southern Switzerland, Bellinzona, Switzerland;

2 Foundation IRCCS Ca' Granda, Ospedale Maggiore Policlinico, University of Milan, Pediatric Unit, Milan, Italy;

${ }^{3}$ Università della Svizzera Italiana, Lugano, Switzerland;

${ }^{4}$ Foundation IRCCS Ca' Granda, Ospedale Maggiore Policlinico, University of Milan, Pediatric Emergency Department, Milan, Italy;

${ }^{5}$ Pediatric Cardiology Unit, Department of Pediatrics, Centre Hospitalier Universitaire Vaudois (CHUV), Lausanne, Switzerland.

* These authors contributed equally to this work.

Short title: Fever phobia

Word Count

- Abstract: 198 words

- Body of the manuscript: 1617 words

Correspondence: Gregorio P Milani, Pediatric unit, Foundation IRCCS Ca' Granda, Ospedale Maggiore Policlinico, via della Commenda 9, 20122 Milan, Italy. Tel: 0039(0)255032628, Fax: 0039(0)255032918, email: milani.gregoriop@gmail.com

KEYWORDS: anxiety; fever phobia; nurses; over treatment; physicians. 


\section{Abstract}

Aim: Fever phobia describes exaggerated concerns about the consequences of childhood fever and broader awareness is needed in everyday clinical practice. We investigated the factors associated with fever phobia in caregivers and healthcare providers and the geographical distribution of the issue.

Method: The National Library of Medicine and Excerpta Medica databases were searched for papers on fever phobia, excluding those that tackled fever phobia.

Results: We retrieved 76 papers, published in English from 19852018, which covered wide areas of Asia, Europe, America, Africa and Australia. Fever phobia was common and 65 papers confirmed the occurrence of fever phobia among 26,521 caregivers. These showed that a number of factors were significantly associated with fever phobia, including low educational or socioeconomic levels, a history of febrile seizures in the child and young maternal age. Fever phobia was also more common in Bedouins and in people from Latin America, Southern Italy and Turkey. There were also 15 papers that addressed fever phobia among 4,566 healthcare providers. All the reports suggested that a fear of fever and a tendency to over treat was common among physicians and nurses.

Conclusion: Fever phobia was a common world phenomena that affected caregivers and healthcare providers.

\section{Key notes}

- We reviewed fever phobia and identified 76 papers published from 1985- 2018 covering 26,521 caregivers and 4,566 healthcare providers.

- This showed that fever phobia was a common world phenomena that affected caregivers and healthcare providers and led to over treatment.

- A number of factors were significantly associated with fever phobia in caregivers, including low educational or socioeconomic 
levels, a history of febrile seizures in the child and young maternal age.

Abbreviations: None 


\section{INTRODUCTION}

Fever is an everyday problem in paediatrics and one of the most common reasons that parents seek medical attention for their child $(1,2)$. Four decades ago, Barton D. Schmitt, a paediatric hospitalist in Denver, invited the parents of children with fever to complete a questionnaire (3). The answers suggested that they were often unduly worried about the consequences of fever and frequently treated fevers too aggressively. As a consequence, the term fever phobia was coined, to denote an exaggerated and irrational fear of fever effects, a tendency to over treat fever or both (3). These fears included concerns about brain damage, learning disabilities, blindness, hearing loss and even death (3). On the other hand, over treatment included the administration of antipyretic drugs in afebrile children with a history of febrile seizures, waking up a child to measure their temperature or the routine use of an alternating regimen of paracetamol and ibuprofen.

Meanwhile, more and more data confirmed that most fever is not dangerous in itself and is a beneficial response to infection (1-3). Since broader awareness of fever phobia is important in everyday clinical practice, we carried out a comprehensive literature search. In particular, we wanted to investigate factors that were potentially associated with caregivers' fever phobia, the occurrence of fever phobia among healthcare providers and the geographical distribution of the phenomena. 


\section{Methods}

Since 1980, when Barton D Schmitt published his seminal paper (3), there have been additional reports that have addressed and tentatively catalogued fever phobia, mostly by using a slightly modified version of his original questionnaire (3). Between January and March 2018, we performed a computer-based search of the terms fever phobia OR pyrexiophobia OR pyrexophobia OR febriphobia with no date limits in the US National Library of Medicine, Excerpta Medica and Google Scholar database. The principles underlying the UK Economic and Social Research Council guidance on the conduct of synthesis and the Preferred Reporting Items for Systematic Reviews and Meta-Analyses statement were applied. Secondary references were also reviewed. For the final analysis, we selected original reports published as full-length papers or letters to the editor, which addressed the issue of misconceptions and unwarranted fears pertaining to fever in children. Reports evaluating possible interventions to tackle fever phobia were excluded. The data were extracted from each of the selected reports using a predefined database form. Studies published in languages other than Dutch, English, French, German, Italian, Portuguese or Spanish were excluded.

The chi-square test was used for statistics and a two-sided value of $p<0.05$ was considered to be statistically significant.

\section{RESULTS}

Search results 
The literature search process is summarised in Figure 1. For the final analysis, we retained 76 papers published between 1985 and 2018 (4-60, S61-S78), which had been published in English between 1985 and 2018. The other languages did not identify any suitable papers. There were 26 papers from Asia: one each from Iraq, the People's Republic of China, the Republic of China, South Korea and the United Arab Emirates, two each from India, Japan, Iran and Saudi Arabia, four from Israel and Malaysia, and five from Turkey. A total of 20 papers came from Europe: one each from Germany, Greece, Ireland, Portugal and Switzerland, two from Denmark, three from the Netherlands, and five each from Italy and the United Kingdom. There were 20 papers from America: one from Mexico, five from Canada and 14 from the United States of America. Five papers came from Australia. Finally, there were five papers from Africa: one each from Kenya and Tanzania, and three from Nigeria.

\section{Fever phobia among caregivers}

The possible occurrence of fever phobia was addressed by 65 papers that covered 26,521 caregivers $(4-8,11-19,21,23-25,27-39,41$ $45,47,48,50,52,53,55-60,561-578)$. Fever phobia was detected in all of the reports.

Factors that predisposed caregivers to fever phobia were addressed in many of the papers. The possible link between fever phobia and either parental educational or socioeconomic level, parental ethnicity, a history of febrile seizures, maternal age or having three or more children in a family were analysed each in at least three reports. 
The possible association between either educational level or socioeconomic status and fever-related anxiety was investigated in 23 papers covering 13,238 families. An association between high educational level or high socioeconomic status and fever phobia was found in four reports covering 1,263 families. Finally, 14 reports covering 9,234 families found that low educational or socioeconomic level were associated with an elevated degree of fever phobia. We therefore concluded that fever phobia was linked with low educational and socioeconomic status.

The possible existence of a relationship between parental ethnicity and fever phobia was addressed in 12 papers covering 3,792 families. All the reports confirmed the existence of such a correlation: in the United States among caregivers of Latin American extraction, in Israel among caregivers belonging to the traditional Bedouin group, in Germany among Turkish migrants and in Italy among caregivers from Southern Italy.

A significant association between the child having a past history of febrile seizures and fever phobia was addressed by three reports covering 1,157 families, and was only found in one large report covering 746 families.

A total of three papers covering 5,027 families speculated that fever phobia was elevated among young mothers. This hypothesis was confirmed in two reports of 4,827 mothers.

The existence of a link between family size and fever-related anxiety was addressed in seven papers covering 6,694 families. Only two reports covering 1,125 children found that having an only child 
predisposed the parents to fever phobia. On the contrary, five articles comprising 5,569 families did not confirm this tendency.

The relationship between the child being young and fever-related anxiety was addressed by two papers covering 538 children and these found an association among 327 Greek but not 211 Dutch mothers. Fever-related anxiety was common among 78 British caregivers who had had previously attended hospital with a febrile child, but not among 211 Japanese caregivers. Finally, a Canadian report on 510 families found that fever phobia was more prominent among caregivers whose children were febrile at the time of interview, compared to the caregivers of children, who were either healthy or presented because of a minor trauma.

The results of studies covering caregivers are summarised in Table 1.

\section{Fever phobia among healthcare providers}

A total of 15 papers addressed the possible occurrence of fever phobia among 4,566 healthcare providers $(9,10,20,22-$ $24,26,40,46,49,51,54,567,568, S 79)$. The papers covered 4,566 physicians and 811 nurses. In one paper on 44 healthcare providers, the physicians and nurses were not separately analysed. All studies suggested that exaggerated fears about the consequences of fever and a tendency to over treat fever were common among healthcare providers. A total of three studies comparing the approach to fever among 1,475 healthcare providers found that, whilst most physicians were aware that fever was beneficial to the body's defence system, many nurses were not. Finally, a Canadian study found that fever 
phobia was more prevalent among family doctors than among general paediatricians.

\section{Geographical distribution of fever phobia}

Table 2, which depicts the geographical distribution of fever phobia, shows that fever phobia was observed among caregivers from all continents. The issue of fever phobia among healthcare providers has so far been addressed in all continents except Africa.

\section{DISCUSSION}

This review, which complemented an analysis published in 2016 (S80) and benefited from the large number of identified original papers, found that fever phobia occurred worldwide among caregivers. Furthermore, healthcare providers also suffered to some extent, from irrational fears of fever and these sometimes resulted in over treatment. This was more common in nurses than physicians.

The data indicated that fever phobia was common among parents with low educational or socioeconomic levels, young mothers, children with past history of febrile seizures and some ethnic groups. On the contrary, no clear-cut correlations were found between fever phobia and family size or the child's age.

The views of healthcare providers about fever phobia is an interesting issue that is likely to have been under-recognised issue. Clinical practice guidelines base standards of care based on evidence-based medicine and prescriptions that do not comply with these guidelines are increasingly being reported. These relate to both under and over-treatment. Under prescribing effective therapies 
is common in conditions such as diabetes, cardiovascular diseases, or obstructive pulmonary diseases, and pain $(\mathrm{S} 81, \mathrm{~S} 82)$. On the other hand, over-treatment is common in acute respiratory and urinary tract infections $(\mathrm{S} 83, \mathrm{~S} 84)$.

Guidelines seek to calm fever phobia in caregivers and healthcare providers by reinforcing the beneficial qualities of fever and encouraging the use of antipyretics for discomfort rather than for temperature control (S85-S87). Complicated febrile convulsions are a frightening experience, but administrating antipyretics at the first sign of fever does not prevent recurrences. On the other hand, prophylactic antiseizure drugs decrease the frequency of recurrent seizures, but the risk of side effects might outweigh the benefits $(\mathrm{S} 85-\mathrm{S} 87)$.

This study had some limitations. First, the heterogeneity of the study designs used in the literature partly precluded a quantitative comparison of the results and an in-depth analysis of the predisposing factors. Second, the studies on fever phobia included in the analysis were based on self-reports, which do not always reflect everyday practice. Third, the questionnaires were filled in in different settings, such as emergency room as compared to the waiting rooms or the waiting rooms of an outpatient clinics, and these could have negatively or positively influenced the anxiety of the responders. Finally, this review does not offer explanations about why healthcare providers do not follow guidelines on fever management.

With respect to the last issue, an ad-hoc conference was held among the authors of this report to try and identify why healthcare 
providers do not follow guidelines on fever management. We considered the factors previously identified as possible barriers for adherence to asthma guidelines (S88). The participants suggested six possible relevant barriers that healthcare providers face when managing febrile children using current guidelines and rated their supposed clinical relevance (Table 3 ).

\section{CONCLUSION}

This survey showed that fever phobia was a worldwide issue that was prevalent among caregivers and healthcare providers. Defining practice guidelines for the symptomatic management of fever in children is only one step in the process of developing evidencebased care.

Appendix S1: references from S61 to 588.

\section{Acknowledgments}

- The authors would like to thank Dr. Alec Villa for his assistance in the linguistic revision.

\section{CONFLICTS OF INTEREST}

The authors have no conflicts of interest to declare.

\section{FINANCE}

This review received no external funding. 


\section{References}

1. El-Radhi AS. Fever management: Evidence vs current practice. World J CLin Pediatr 2012; 1: 29-33.

2. Bertille N, Purssell E, Hjelm N, Bilenko N, Chiappini E, de Bont EGPM et al. Symptomatic management of febrile illnesses in children: a systematic review and meta-analysis of parents' knowledge and behaviors and their evolution over time. Front Pediatr 2018; 6: 279. 3. Schmitt BD. Fever phobia: misconceptions of parents about fevers. Am J Dis Child 1980; 134: 176-81.

4. Kramer MS, Naimark L, Leduc DG. Parental fever phobia and its correlates. Pediatrics 1985; 75: 1110-13.

5. Andersen AR. Parental perception and management of school-age children's fevers. Nurse Pract 1988; 13: 8-18.

6. Stephenson MJ, Rosencrantz A, Kneller P. Childhood fever: parental beliefs and management Can Fam Physician 1988; 34: 63-6. 7. Singhi S, Singh S. Fever: maternal knowledge, attitude and treatment practices in a rural area. Indian Pediatr 1990; 27: 11036.

8. Singhi S, Padmini $P$, Sood V. Urban parents' understanding of fever in children: its dangers, and treatment practices. Indian Pediatr 1991; 28: 501-5.

9. May A, Bauchner H. Fever phobia: the pediatrician's contribution. Pediatrics 1992; 90: 851-4.

10. Ipp M, Jaffe D. Physicians' attitudes toward the diagnosis and management of fever in children 3 months to 2 years of age. Clin Pediatr (Phila) 1993; 32: 66-70.

11. Kai J. What worries parents when their preschool children are acutely ill, and why: a qualitative study. BMJ 1996; 313: 983-6. 12. Kelly L, Morin K, Young D. Improving caretakers' knowledge of fever management in preschool children: is it possible? J Pediatr Health Care 1996; 10: 167-73. 
13. Rendon-Macias ME, Tellez-Leon G, Reyes-Valencia G, Apresa-Garcia T. Fever phobia as a cause of overtreatment in children. Bol Med Hosp Infant Mex 1996; 53: 374-84.

14. Blumenthal I. What parents think of fever. Fam Pract 1998; 15: 513-8.

15. Impicciatore P, Nannini S, Pandolfini C, Bonati M. Mother's knowledge of, attitudes toward, and management of fever in preschool children in Italy. Prev Med 1998; 27: 268-73.

16. Parkinson GW, Gordon KE, Camfield CS, Fitzpatrick EA. Anxiety in parents of young febrile children in a pediatric emergency department: why is it elevated? Clin Pediatr (Phila) 1999; 38: 21926.

17. van Stuijvenberg M, de Vos S, Tjiang GC, Steyerberg EW, DerksenLubsen G, Moll HA. Parents' fear regarding fever and febrile seizures. Acta Paediatr 1999; 88: 618-22.

18. Al-Eissa YA, Al-Sanie AM, Al-Alola SA, Al-Shaalan MA, Ghazal SS, Al-Harbi AH et al. Parental perceptions of fever in children. Ann Saudi Med 2000; 20: 202-5.

19. Al-Eissa YA, al-Zamil FA, al-Sanie AM, al-Salloum AA, alTuwaijri HM, al-Abdali NM et al. Home management of fever in children: rational or ritual? Int J CLin Pract 2000; 4: 138-42. 20. Al-Eissa YA, Al-Zaben AA, Al-Wakeel AS, Al-Alola SA, Al-Shaalan MA, Al-Amir AA et al. Physician's perceptions of fever in children Facts and myths. Saudi Med J 2001; 22: 124-8.

21. Crocetti M, Moghbeli N, Serwint J. Fever phobia revisited: have parental misconceptions about fever changed in 20 years? Pediatrics 2001; 107: 1241-6.

22. Edwards HE, Courtney MD, Wilson JE, Monaghan SJ, Walsh AM. Fever management practises: what pediatric nurses say. Nurs Health Sci 2001; 3: 119-30.

23. Karwowska A, Nijssen-Jordan C, Johnson D, Davies HD. Parental and health care provider understanding of childhood fever: a Canadian perspective. CJEM 2002; 4: 394-400. 
24. Sarrell M, Cohen HA, Kahan E. Physicians', nurses', and parents' attitudes to and knowledge about fever in early childhood. Patient Educ Couns 2002; 46: 61-5.

25. Taveras EM, Durousseau S, Flores G. Parents' beliefs and practices regarding childhood fever: a study of a multiethnic and socioeconomically diverse sample of parents. Pediatr Emerg Care 2004; 20: 579-87.

26. Walsh AM, Edwards HE, Courtney MD, Wilson JE, Monaghan SJ. Fever management: paediatric nurses' knowledge, attitudes and influencing factors. J Adv Nurs 2005; 49: 453-64.

27. Al-Nouri L, Basheer K. Mothers' perceptions of fever in children. J Trop Pediatr 2006; 52: 113-7.

28. Betz MG, Grunfeld AF. "Fever phobia" in the emergency department: a survey of children's caregivers. Eur J Emerg Med 2006; 13: $129-33$.

29. Walsh A, Edwards H, Fraser J. Influences on parents' fever management: beliefs, experiences and information sources. J Clin Nurs 2007; 16: 2331-40.

30. Matziou V, Brokalaki H, Kyritsi H, Perdikaris P, Gymnopoulou E, Merkouris A. What Greek mothers know about evaluation and treatment of fever in children: an interview study. Int J Nurs Stud 2008; 45: 829-36.

31. Oshikoya KA, Senbanjo IO. Fever in children: mothers' perceptions and their home management. Iran J Pediatr 2008; 18: 22936.

32. Tessler H, Gorodischer R, Press J, Bilenko N. Unrealistic concerns about fever in children: the influence of cultural-ethnic and sociodemographic factors. Isr Med Assoc J 2008; 10: 346-9.

33. Walsh A, Edwards H, Fraser J. Parents' childhood fever management: community survey and instrument development. J Adv Nurs 2008; 63: 376-88.

34. Crocetti M, Sabath B, Cranmer L, Gubser S, Dooley D. Knowledge and management of fever among Latino parents. CLin Pediatr (Phila) 2009; 48: 183-9. 
35. Purssell E. Parental fever phobia and its evolutionary correlates. J CLin Nurs 2009; 18: 210-8.

36. Sakai R, Marui E. Fever phobia; can we blame the trend to nuclear family or having a single child? Acta Paediatr 2009; 98: 405-7.

37. Cohee LM, Crocetti MT, Serwint JR, Sabath B, Kapoor S. Ethnic differences in parental perceptions and management of childhood fever. Clin Pediatr (Phila) 2010; 49: 221-7.

38. Erichsen D, Ali M. Parental perceptions of fever in children; a qualitative approach. $N$ Y Med J 2010; 5: 170-4.

39. Erkek N, Senel S, Sahin M, Ozgur 0, Karacan C. Parents' perspectives to childhood fever: comparison of culturally diverse populations. J Paediatr Child Health 2010; 46: 583-7.

40. Meehan WP 3rd, Fleegler E, Bachur RG. Adherence to guidelines for managing the well-appearing febrile infant: assessment using a case-based, interactive survey. Pediatr Emerg Care 2010; 26: 875-80.

41. Nijman RG, Oostenbrink R, Dons EM, Bouwhuis CB, Moll HA. Parental fever attitude and management: influence of parental ethnicity and child's age. Pediatr Emerg Care 2010; 26: 339-342. 42. Poirier MP, Collins EP, McGuire E. Fever phobia: a survey of caregivers of children seen in a pediatric emergency department. Clin Pediatr (Phila) 2010; 49: 530-4.

43. Rupe A, Ahlers-Schmidt CR, Wittler R. A comparison of perceptions of fever and fever phobia by ethnicity. Clin Pediatr (Phila) 2010; 49: 172-6.

44. Alex-Hart BA, Frank-Briggs AI Mothers' perception of fever management in children. Niger Health $\mathrm{J}$ 2011; 11: 69-72.

45. Langer T, Pfeifer M, Soenmez A, Tarhan B, Jeschke E, Ostermann T. Fearful or functional- a cross-sectional survey of the concepts of childhood fever among German and Turkish mothers in Germany. BMC Pediatr 2011; 11:41.

46. Wood N, Powell C. Healthcare staff views on fever: are we contributing to fever phobia? Welsh Paediatr J 2011; 35: 40-3. 
47. Arica SG, Arica V, Onur H, Gülbayzar S, Dağ H, Obut Ö. Knowledge, attitude and response of mothers about fever in their children. Emerg Med J 2012; 29:e4.

48. Chiappini E, Parretti A, Becherucci P, Pierattelli M, Bonsignori F, Galli L et al. Parental and medical knowledge and management of fever in Italian pre-school children. BMC Pediatr 2012; 12:97.

49. Demir F, Sekreter 0. Knowledge, attitudes and misconceptions of primary care physicians regarding fever in children: a cross sectional study. Ital J Pediatr 2012; 38:40.

50. Enarson MC, Ali S, Vandermeer B, Wright RB, Klassen TP, Spiers JA. Beliefs and expectations of Canadian parents who bring febrile children for medical care. Pediatrics 2012; 130: e905-12.

51. Lava SAG, Simonetti GD, Ramelli GP, Tschumi S, Bianchetti MG. Symptomatic management of fever by Swiss board-certified pediatricians: results from a cross-sectional, Web-based survey. Clin Ther 2012; 34: 250-6.

52. Sakai R, Okumura A, Marui E, Niijima S, Shimizu T. Does fever phobia cross borders? The case of Japan. Pediatr Int 2012; 54: 3944 .

53. Chang LC, Liu CC, Huang MC. Parental knowledge, concerns, and management of childhood fever in Taiwan. J Nurs Res 2013; 21: 25260 .

54. Greensmith L. Nurses' knowledge of and attitudes towards fever and fever management in one Irish children's hospital. J Child Health Care 2013; 17: 305-16.

55. Kwak YH, Kim do K, Jang HY, Kim JJ, Ryu JM, Oh SB et al. Fever phobia in Korean caregivers and its clinical implications. J Korean Med Sci 2013; 28: 1639-44.

56. Wallenstein MB, Schroeder AR, Hole MK, Ryan C, Fijalkowski N, Alvarez E et al. Fever literacy and fever phobia. Clin Pediatr (Phila) 2013; 52: 254-9.

57. Zyoud SH, Al-Jabi SW, Sweileh WM, Nabulsi MM, Tubaila MF, Awang $\mathrm{R}$ et $\mathrm{al}$. Beliefs and practices regarding childhood fever among 
parents: a cross-sectional study from Palestine. BMC Pediatr 2013; 13: 66 .

58. De S, Tong A, Isaacs D, Craig JC. Parental perspectives on evaluation and management of fever in young infants: an interview study. Arch Dis Child 2014; 99: 717-23.

59. Polat M, Kara S, Tezer H, Tapısız A, Derinöz O, Dolgun A. A current analysis of caregivers' approaches to fever and antipyretic usage. J Infect Dev Ctries 2014; 8: 365-371.

60. Ravanipour M, Akaberian S, Hatami G. Mothers' perceptions of fever in children. J Educ Health Promot 2014; 3: 97.

\section{Figure's legend}

\section{Figure 1}

Fever phobia. Flowchart of the literature search process. 
Table 1: Factors possibly associated with parental fever phobia.

Significance

- Low educational and socioeconomic status

$\mathrm{P}<0.0001$

- Ethnicity (Latin Americans, Bedouins, Turkish, Southern Italians)

$P<0.001$

- Past history of febrile seizures

$P<0.0001$

- Young maternal age

$p<0.0001$

- Child's age

not significant

- Family size ( $\geq 3$ children)

not significant

- Having a febrile child not significant 
Table 2: Geographical distribution of fever phobia among caregivers and healthcare providers.

\begin{tabular}{llll}
\hline Continent & Reports (N) & Caregivers (N) & Healthcare \\
& & & providers (N) \\
\hline Africa & 5 & 2,189 & - \\
America & 20 & 5,573 & 369 \\
Asia & 26 & 13,786 & 1,552 \\
Europe & 20 & 4,521 & 2,579 \\
Oceania & 5 & 452 & 66 \\
& & & \\
\hline
\end{tabular}


Table 3: Set of barriers associated with non-adherence to guidelines suggested in the literature [S88], examples of barriers possibly underlying over-treatment of fever among healthcare providers and presumed relevance (classified in an ad-hoc conference among authors). Relevance was scored as high, moderate or low.

General barriers Example

Relevance

underlying non-

adherence

Poor awareness or

familiarity

Inertia of previous

practice

Poor agreement
Guidelines presented in

High

exceedingly long documents

Healthcare workers manage fever

High

the way they have always done

Guidelines recommending

High

elimination of traditional

aggressive pharmacotherapy of

fever are more difficult to

implement than guidelines adding

supplemental pharmacotherapy

Healthcare workers believe that Moderate

antipyretics partly prevent

reappearance of febrile seizures 


$\begin{array}{ll}\text { Lack of self-efficacy } & \begin{array}{l}\text { Lack of time (and reimbursement) Low } \\ \text { for parental education about fever }\end{array} \\ & \\ \text { Lack of outcome } & \text { Expectation that parental Moderate } \\ \text { expectancy } & \text { education about fever will not } \\ & \text { lead to any consequence }\end{array}$

